\title{
Cervicothoracic sympathetic system in the dog: new insights by the gross morphological description of each ganglion with its branches on each side
}

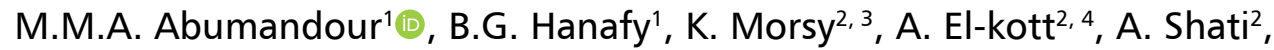 \\ E. Salah EL-Din ${ }^{3,5}$, N.F. Bassuoni ${ }^{1}$ \\ ${ }^{1}$ Anatomy and Embryology Department, Faculty of Veterinary Medicine, Alexandria University, Alexandria, Egypt \\ ${ }^{2}$ Biology Department, College of Science, King Khalid University, Abha, Saudi Arabia \\ ${ }^{3}$ Zoology Department, Faculty of Science, Cairo University, Cairo, Egypt \\ ${ }^{4}$ Zoology Department, Faculty of Science, Damanhour University, Damanhour, Egypt \\ ${ }^{5}$ Biology Department, Faculty of Science, Bisha University, Bisha, Saudi Arabia
}

[Received: 3 December 2020; Accepted: 17 January 2021; Early publication date: 29 January 2021]

Background: Much published data exists on the position of cervicothoracic ganglion, but a little published research has been done on the cervicothoracic system of dog. Herein, we illustrated topographical position and shape of each ganglion of cervicothoracic system to determine the distribution of nerves dispersing from them on two sides, left and right.

Materials and methods: Our work designed on the usage of 10 healthy adult dogs. Left cervicothoracic sympathetic system is represented by two ganglia: caudal and middle ganglion, while the right system is represented by three ganglia: caudal, middle cervical and small accessory ganglia.

Results: Left caudal cervical ganglion was elongated triangular, while the right one was elongated spindle in shape. Left caudal cervical ganglion was located on lateral surface of longus colli muscle, at the first intercostal space, while the right one was located at the level of the second rib. Left middle cervical ganglion was ovoid in shape and located at the first intercostal space, while the right one was located at the level of the second rib. There were two nerve trunks forming ansa subclavian trunk on both sides. There were three sympathetic-parasympathetic communicating branches on both sides.

Conclusions: Our study recorded the first observation of left pericardial branch in dog, which originated from the caudal angle of middle cervical ganglion. There was a small ganglion located on the lateral surface of trachea at the level of the first rib. (Folia Morphol. 2022; 81, 1 : 20-30)

Key words: caudal cervical ganglion, middle cervical ganglion, accessory cervical ganglion, ansa subclavia, dog

\section{INTRODUCTION}

The accumulating body of evidence recorded that the autonomic sympathetic nervous system is formed from nerves and ganglia [6]. Furthermore, several reports have described that the ganglia make communication between the central nervous system from one

Address for correspondence: Assist. Prof. M. Abumandour, Anatomy and Embryology, Faculty of Veterinary Medicine, Alexandria University, Alexandria, Egypt, Post Box: 22758, tel: +201282586488, fax: +20452960450, e-mail: m.abumandour@yahoo.com or M.abumandour@alexu.edu.eg

This article is available in open access under Creative Common Attribution-Non-Commercial-No Derivatives 4.0 International (CC BY-NC-ND 4.0) license, allowing to download articles and share them with others as long as they credit the authors and the publisher, but without permission to change them in any way or use them commercially. 
side to the viscera on the other side of the body. In the cervical region, the ganglia of the sympathetic chain are classified into three bilaterally situated ganglia: cranial, middle, and caudal cervical ganglion $[1,6,9$, $13,22]$. Sometimes, another ganglia may be present on the vertebral nerve named vertebral ganglion [22].

The caudal cervical or the stellate ganglion was described previously in many published articles in different animals $[1,6,8,14,17,19]$. Moreover, as recorded in several reports, the cervicothoracic system with its all nerves give an autonomic sympathetic innervation of the forelimb, cervical region, and the organs included in the chest region $[1,10,21]$.

There were several published anatomical books mentioning the position of the cervicothoracic ganglia in the dog. However, to date, a scanty report recorded the cervicothoracic ganglia in Baladi dogs. The current investigation was prepared to illustrate the cervicothoracic system and describe the topographical position, shape of the caudal and middle cervical ganglion on each side and their relationship with the surrounding structures and the nerves dispersing from them. Finally, the obtained data were compared to those reported in other animal species.

\section{MATERIALS AND METHODS}

\section{Animals}

Ten healthy adult dogs of both sexes (sexes and body weights were not recorded) were collected from the Kafrelsheikh Governorate and transported to the anatomical lab of the Anatomy and Embryology Department of the Faculty of Veterinary Medicine, Alexandria University, Egypt to make the anatomical studies. The dog considered the famous canine species. The Baladi dog is the famous dog in Egyptian street. The dog belongs to carnivore order, Canidae family, canis genus, canis iupus species, and canis iupus familiaris (Linnaeus, 1758) subspecies [4, 23].

This study followed the guidelines for the care and use of laboratory animals and the animal welfare and was approved by the Ethics Committee of the Faculty of Veterinary Medicine, Alexandria University according the Egyptian laws. Adequate measures were taken to minimize pain or discomfort of examined animals.

\section{Preparation of animals}

The collected dogs were given an injection of acepromazine $(0.05 \mathrm{mg} / \mathrm{kg} / \mathrm{IM})$, and after $10 \mathrm{~min}$ injection of xylazine $(0.2 \mathrm{mg} / \mathrm{kg}$ of body weight/IM) and atropine
$(0.04 \mathrm{mg} / \mathrm{kg})$. All dogs were well bled via a cannula placed in the common carotid artery; the cannula was subsequently used as an inflow port for injection of $10 \%$ formalin solution through the common carotid artery to fix the specimens, and then, after specimens had been stored for 2 weeks, the fixation process was completed. The anatomical dissection technique was carried out on both sides of all dogs to describe the topographical position, shape, and branches of the ganglia. The dissected dogs were photographed by means of a digital camera (Canon IXY 325, Japan). The measurements were carried out by utilising digital callipers. The quantitative results were expressed as mean \pm standard deviation. The anatomical terms followed the Nomina Anatomica Veterinaria [18].

\section{RESULTS}

\section{Anatomical description of the left cervicothoracic} sympathetic system

The left cervicothoracic sympathetic system was represented by the presence of the two ganglia: the caudal (cervicothoracic) and the middle cervical ganglion (Figs. 1-5; $G$ and $M$ ), in addition to one or more thoracic ganglia. The caudal cervical (cervicothoracic) ganglion was elongated triangular in shape with its apex ventrally and located on the lateral surface of the longus colli muscle, at the first intercostal space. The cranial $1 / 4$ of the examined ganglion was crossed laterally by the first thoracic spinal nerve of the brachial plexus and the costocervical artery (Figs. 1 and 2).

In all examined dogs, the formation of the caudal cervical ganglion (cervicothoracic) achieved by the union of the last (eighth) cervical sympathetic nerve and the first two thoracic sympathetic ganglia. There were several rami communicantes received by the caudal cervical ganglion, which were originated from the eight cervical and the first two thoracic spinal segments. These rami communicantes originating from the first two thoracic spinal segments were united with the sympathetic trunk to combine with the caudal cervical ganglion at its caudodorsal angle (Figs. $1-5 ; b$ and $c$ ). The ramus communicans named the eight cervical spinal segments was combined with the caudal cervical ganglion at its craniodorsal border (Figs. 1-5; a).

Middle cervical ganglion (Figs. 1-5; M) was ovoid or, in some cases, spindle in shape. It was located at the same level of the caudal cervical ganglion, at the first intercostal space or at the level of the second rib (2 cases). 


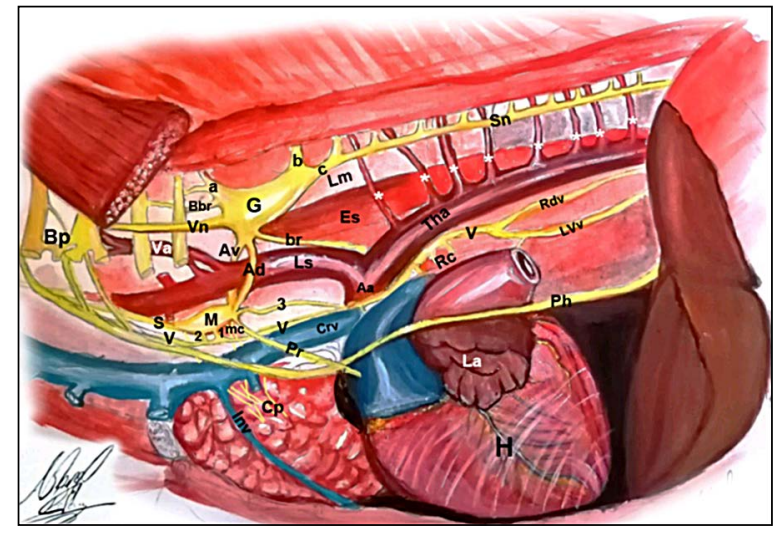

Figure 1. Illustrated image to describe the left cervicothoracic system of dog; G — left cervicothoracic ganglion; $\mathrm{M}$ - middle cervical ganglion; a - last (eighth) cervical sympathetic nerve; b - first thoracic sympathetic ganglion; $c$ - second thoracic sympathetic ganglion; br - the nerve to brachiocephalic trunk; $\mathrm{Bbr}$ - ramus communicans combined with the thoracic spinal nerve to share in the formation of the brachial plexus; $\mathrm{Ad}$ - lateral small ansa subclavia nerve; $\mathrm{Av}$ - medial large ansa subclavia nerve; $\mathrm{Pr}$ - pericardial branch; 3 - the long caudally directed sympathetic-parasympathetic communicating branch; $\mathrm{mc}$ — cardiac nerves; $\mathrm{Aa}$ - aortic arch; Ls — left subclavian artery; Tha — thoracic aorta; white stars refer to the intercostal arteries; Es - oesophagus; $\mathrm{Lm}$ - longus colli muscle; Va - vertebral artery; $\mathrm{Vn}$ - vertebral nerve; $\mathrm{Sn}$ - sympathetic nerve; Inv — internal thoracic vein; $\mathrm{V}$ - vagus nerve; Ldv — left dorsal vagus nerve; Lvv — left ventral vagus nerve; $\mathrm{Ph}$ - phrenic nerve; $\mathrm{H}$ - heart; $\mathrm{La}$ - left atrium; Crv — cranial venea cavae.

Its dorsal $1 / 4$ was covered laterally by the left subclavian artery before its bifurcation into common carotid, internal thoracic and axillary arteries. The middle cervical ganglion communicated with the caudal cervical ganglion by two nerve trunks forming the left ansa subclavia. After it left the vagosympathetic nerve trunk, the cervical part of the sympathetic nerve trunk was combined with the middle cervical ganglion at its cranial angle.

\section{Branches dispersing from the left caudal cervical ganglion}

\section{The vertebral nerve}

The vertebral nerve (Figs. 1 and 2; $\mathrm{Vn}$ ) was a large nerve that originated from the cranial angle of the triangular caudal cervical ganglion. Then, it passed in the craniodorsal direction on the lateral surface of the longus colli muscle and was covered laterally by the last cervical and the first thoracic spinal nerve. During its course, it was corresponding with the vertebral artery and vein (Figs. 1-3; Va and Vv), after that, they passed under the transverse process of the seventh cervical vertebrae and entered the transverse foramen of the sixth cervical vertebrae.

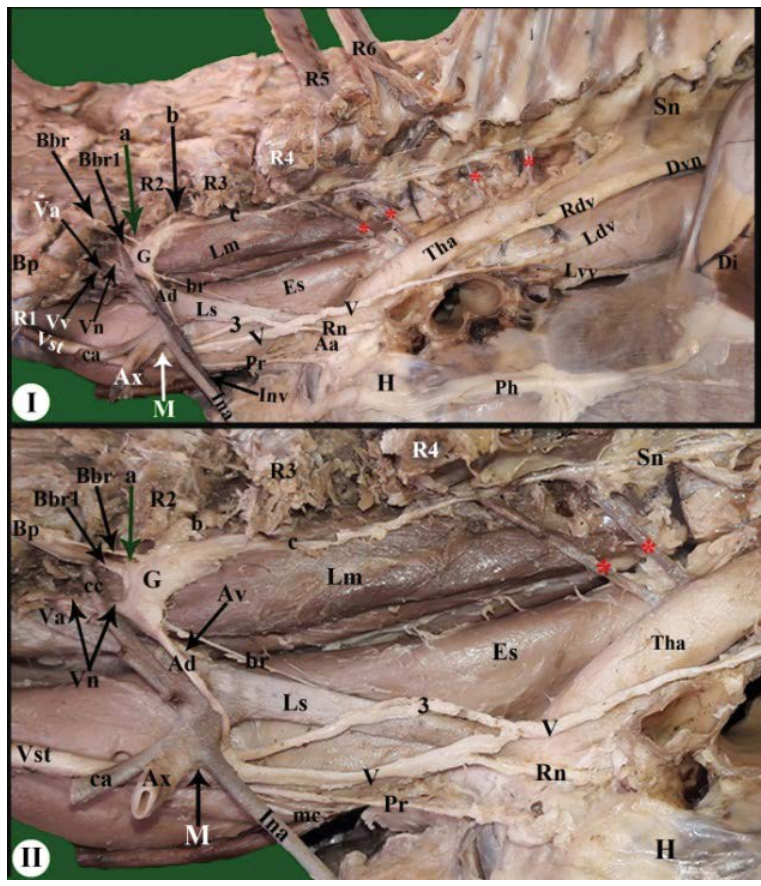

Figure 2. Gross anatomical photographs of the lateral macroscopic appearance of left cervicothoracic ganglion after the cranial reflection of the first rib (R1), removal of succeeding three ribs (R2-R4), reflection of fifth and sixth ribs (R5 and R6), and elevation of brachial plexus (Bp): View I with the presence of left subclavian vein and its branches and view II after removal of left subclavian vein and its branches; $\mathrm{G}$ - left cervicothoracic ganglion; $\mathrm{M}$ - middle cervical ganglion; a — last (eighth) cervical sympathetic nerve; b - first thoracic sympathetic ganglion; c - second thoracic sympathetic ganglion; br - the nerve to brachiocephalic trunk; $\mathrm{Bbr}$ - a long ramus communicans combined with the first thoracic spinal nerve to share in the formation of the brachial plexus; Bbr1 - short ramus communicans combined with the first thoracic spinal nerve to share in the formation of the brachial plexus; Ad lateral small ansa subclavia nerve; $\mathrm{Av}$ - medial large ansa subclavia nerve; $\operatorname{Pr}$ - pericardial branch; 3 - the long caudally directed sympathetic-parasympathetic communicating branch; mc — cardiac nerves; Aa — aortic arch; Ls — left subclavian artery; Tha thoracic aorta; Es - oesophagus; Lm — longus colli muscle; cc - costocervical artery; $\mathrm{Va}$ - vertebral artery; $\mathrm{Vv}$ - vertebral vein; $\mathrm{Vn}$ - vertebral nerve; ca — common carotid artery; Vst vagosympathetic trunk; $\mathrm{Sn}$ - sympathetic nerve; $\mathrm{Ax}$ - axillary artery; Ina — internal thoracic artery; Inv — internal thoracic vein; red asterisk — intercostal arteries; V — vagus nerve; Ldv — left dorsal vagus nerve; Rdv — left dorsal vagus nerve; Lvv — left ventral vagus nerve; Dvn — dorsal vagal nerve trunk; $\mathrm{Di}$ - diaphragm; $\mathrm{Ph}$ - phrenic nerve; $\mathrm{H}$ - heart; $\mathrm{Rn}$ - recurrent laryngeal nerve.

\section{The ansa subclavian nerve}

The ansa subclavia was the nerve dispersing from the caudal cervical ganglion and wrapped around the left subclavian artery. The left ansa subclavia consisted of two nerve trunks originating from the caudoventral angle of the caudal cervical ganglion and named: the lateral small branch and the medial large branch (Figs. 1-5; Ad and Av). 


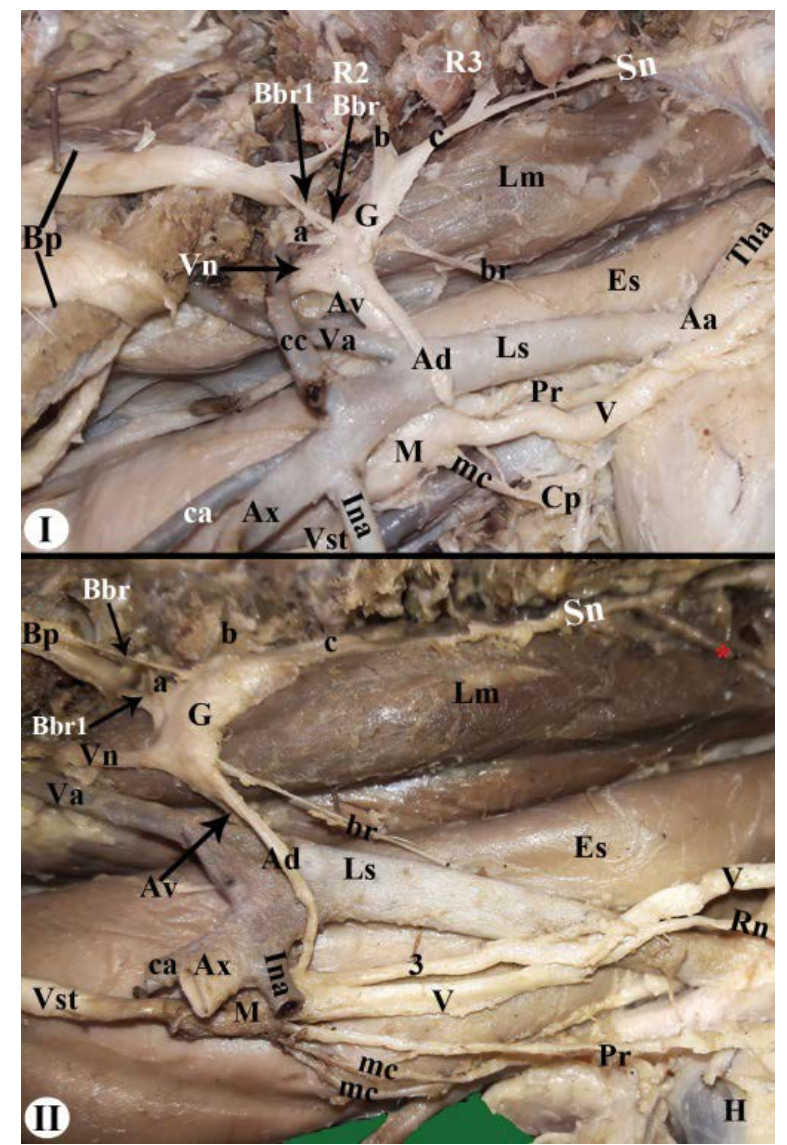

Figure 3. Gross anatomical photographs of lateral macroscopic appearance of the left cervicothoracic ganglion after the removal of first four ribs (R1-R4), and the elevation of brachial plexus (Bp); View I revelaed the presence of left subclavian vein and its branches while; View II revelaed the removal of left subclavian vein and its branches; $\mathrm{G}$ - left cervicothoracic ganglion; $\mathrm{M}$ - middle cervical ganglion; $a$ - last (eighth) cervical sympathetic nerve; $b$ first thoracic sympathetic ganglion; $\mathrm{c}$ - second thoracic sympathetic ganglion; $\mathrm{br}$ - nerve to brachiocephalic trunk; $\mathrm{Bbr}$ - a long ramus communicans combined with the first thoracic spinal nerve to share in the formation of the brachial plexus; Bbr1 - short ramus communicans combined with the first thoracic spinal nerve to share in the formation of the brachial plexus; $b r$ - nerve to the brachiocephalic trunk; Ad — lateral small ansa subclavia nerve; $\mathrm{Av}$ - medial large ansa subclavia nerve; $\mathrm{Pr}$ - pericardial branch; 3 - the long caudally directed sympathetic-parasympathetic communicating branch; $\mathrm{mc}$ - cardiac nerves; $\mathrm{Cp}$ - cardiac plexus; $\mathrm{Aa}$ - aortic arch; Ls - left subclavian artery; Tha — thoracic aorta; Es — oesophagus; Lm — longus colli muscle; cc — costocervical artery; $\mathrm{Va}$ - vertebral artery; $\mathrm{Vn}$ - vertebral nerve; ca - common carotid artery; Vst — vagosympathetic trunk; Sn - sympathetic nerve; Ax - axillary artery; Ina — internal thoracic artery; red star — intercostal artery; $\mathrm{V}$ — vagus nerve; $\mathrm{H}$ - heart; $\mathrm{Rn}$ - recurrent laryngeal nerve.

The lateral small branch (Figs. 1-5; Ad) was directed oblique ventrally and passed on the lateral surface of the left subclavian artery, and then fused with the medial large branch of the ansa subclavia, entered the middle cervical ganglion as one nerve trunk from
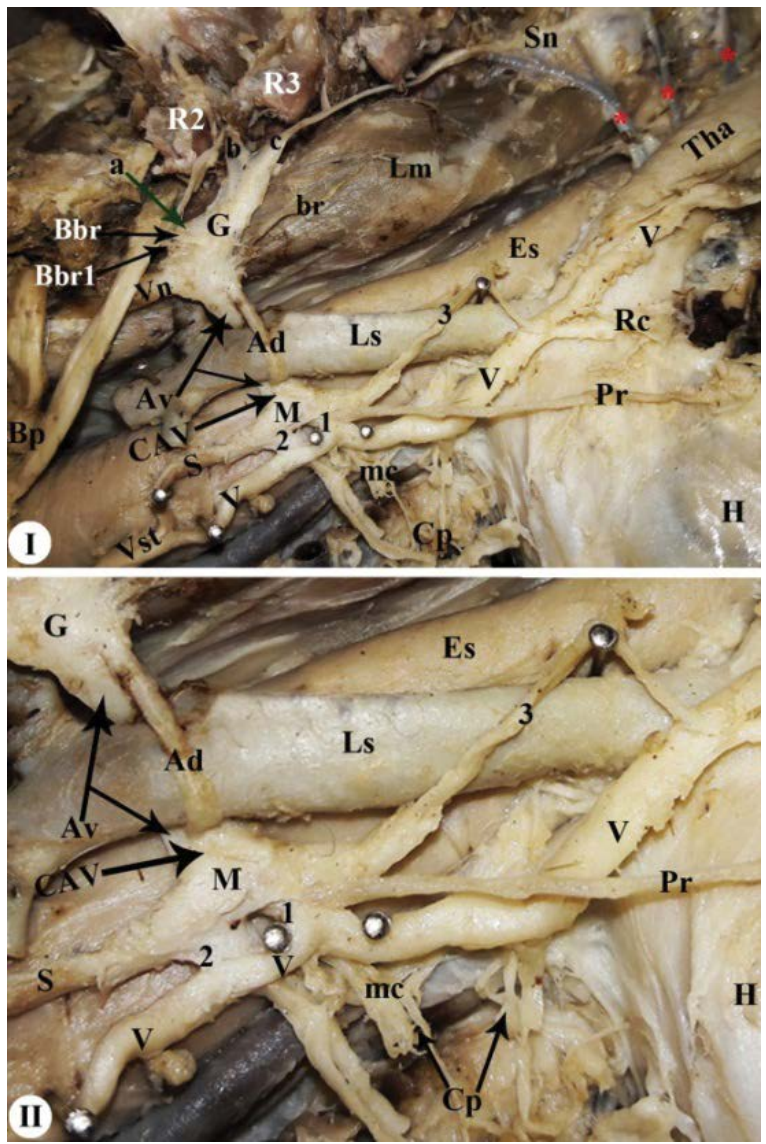

Figure 4. Gross anatomical photographs of lateral macroscopic appearance of the left cervicothoracic ganglion after the removal of first four ribs (R1-R4), and the elevation of brachial plexus (Bp); View I revelaed the presence of left subclavian vein and its branches while; View II revelaed the removal of left subclavian vein and its branches; $\mathrm{G}$ - left cervicothoracic ganglion; $\mathrm{M}$ - middle cervical ganglion; a — last (eighth) cervical sympathetic nerve; b - first thoracic sympathetic ganglion; c - second thoracic sympathetic ganglion; $\mathrm{br}$ - the nerve to brachiocephalic trunk; $\mathrm{Bbr}$ - a long ramus communicans combined with the first thoracic spinal nerve to share in the formation of the brachial plexus; Bbr1 - short ramus communicans combined with the first thoracic spinal nerve to share in the formation of the brachial plexus; $\mathrm{Ad}$ - lateral small ansa subclavia nerve; $\mathrm{Av}$ - medial large ansa subclavia nerve; CAV — common ansa subclavia nerve; $\mathrm{Vn}$ vertebral nerve; $\mathrm{Pr}$ — pericardial branch; 1 and 2 - represent the two-short sympathetic-parasympathetic communicating branch; 3 - the long caudally directed sympathetic-parasympathetic communicating branch; $\mathrm{mc}$ - cardiac nerves; $\mathrm{Cp}$ - cardiac plexus; Ls - left subclavian artery; Tha - thoracic aorta; Es — oesophagus; Lm — longus colli muscle; Vst — vagosympathetic trunk; $\mathrm{S}$ - sympathetic trunk; $\mathrm{Sn}$ - sympathetic nerve; red asterisk intercostal arteries; $\mathrm{V}$ - vagus nerve; $\mathrm{H}$ - heart; $\mathrm{Rn}$ - recurrent laryngeal nerve.

its dorsal arch and embedded directly in the body of the middle cervical ganglion (Figs. 1-4; CAV). While the medial large branch of the ansa subclavia passed medially to the left subclavian artery and on the lateral surface of the oesophagus (Figs. 1-5; Ad and Av) 


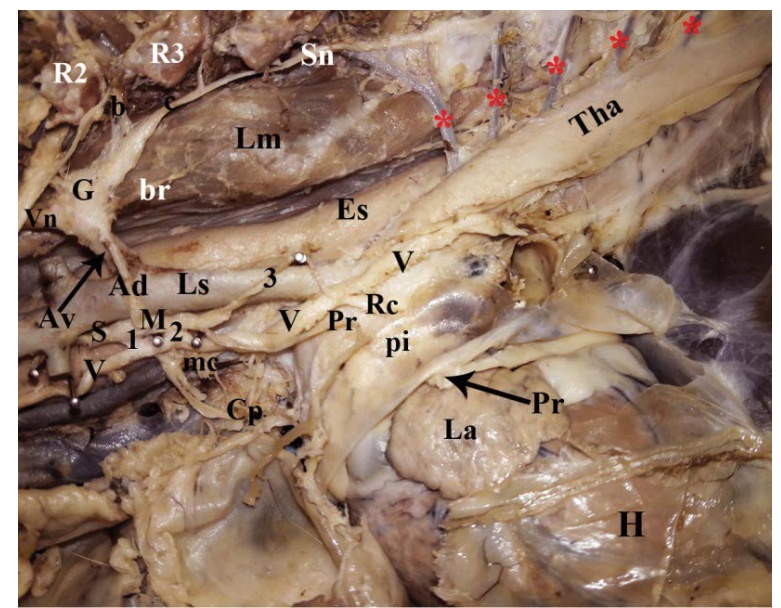

Figure 5. Gross anatomical photographs of lateral macroscopic appearance of the left cervicothoracic ganglion; $\mathrm{G}$ - left cervicothoracic ganglion; $\mathrm{M}$ - middle cervical ganglion; $\mathrm{b}$ - first thoracic sympathetic ganglion; c - second thoracic sympathetic ganglion; $\mathrm{br}$ - the nerve to brachiocephalic trunk; Ad — lateral small ansa subclavia nerve; $\mathrm{Av}$ - medial large ansa subclavia nerve; $\mathrm{Vn}$ vertebral nerve; $\operatorname{Pr}$ - pericardial branch; 1 and 2 - represent the two-short sympathetic-parasympathetic communicating branch; 3 - the long caudally directed sympathetic-parasympathetic communicating branch; $\mathrm{mc}$ - cardiac nerves; $\mathrm{Cp}$ - cardiac plexus; Ls — left subclavian artery; Tha — thoracic aorta; Es — oesophagus; $\mathrm{Lm}$ — longus colli muscle; $\mathrm{Sn}$ - sympathetic nerve; red asterisk — intercostal arteries; $\mathrm{V}$ - vagus nerve; $\mathrm{H}$ - heart; $\mathrm{Rn}$ - recurrent laryngeal nerve; $\mathrm{pi}$ - pericardium; $\mathrm{La}$ — left atrium.

until it united with the lateral one forming the common trunk that embedded directly in the body of the middle cervical ganglion.

\section{The nerve to the brachiocephalic trunk}

It was the smaller branch dispersing from the caudoventral border of the caudal cervical ganglion near to its caudoventral angle, and then directed caudoventrally to the medial surface of the brachiocephalic and the left subclavian artery (Figs. 1-5; br).

\section{The rami communicants}

There were two rami communicants combined with the first thoracic spinal nerve to share in the formation of the brachial plexus. These two rami communicants originated from the craniodorsal border of the caudal cervical ganglion. These two rami communicants were described as: a short and long one (Figs. 1-3; Bbr and Bbr1). In 2 cases of the examined dogs, there was only one ramus communicans to the first thoracic spinal nerve.

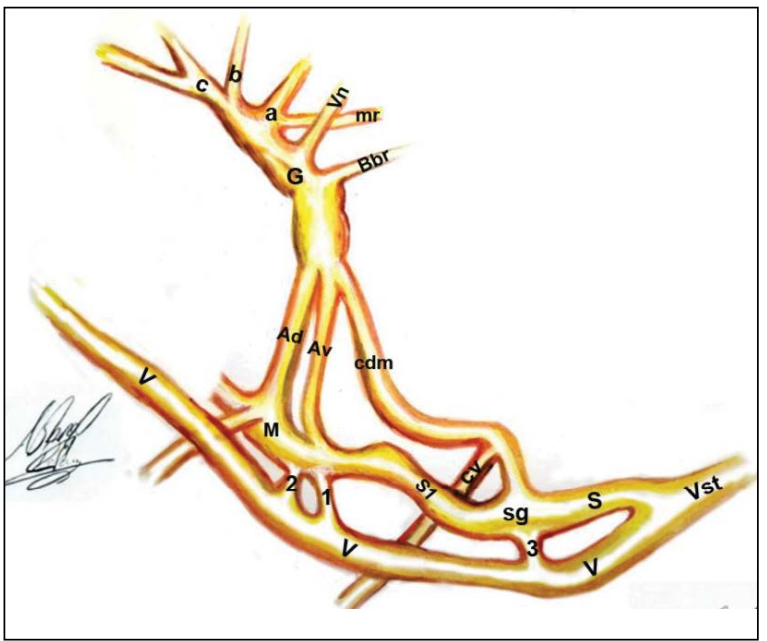

Figure 6. Illustrated image to describe the right cervicothoracic system of dog; $\mathrm{G}$ - right cervicothoracic ganglion; $\mathrm{M}$ - middle cervical ganglion; a — last (eighth) cervical sympathetic nerve; b - first thoracic sympathetic ganglia; c - second thoracic sympathetic ganglia; $\mathrm{mr}$ - muscular branch from right cervicothoracic ganglia; $\mathrm{Bbr}$ - the ramus communicans combined with the last cervical spinal nerve to share in the formation of the brachial plexus; $\mathrm{Ad}$ - lateral small ansa subclavia nerve; $\mathrm{Av}$ — medial large ansa subclavia nerve; $\mathrm{cdm}$ - the cranioventrally directed nerve; $\mathrm{Vn}$ - vertebral nerve; $\mathrm{Cr}$ — the caudal cardiac nerve; $\mathrm{V}$ - vagus nerve; Vst — vagosympathetic trunk; $\mathrm{Sn}$ - sympathetic nerve; $\mathrm{S} 1$ - communicating sympathetic branch between the middle and the small ganglia; sg — small ganglion; $\mathrm{cv}$ - caudoventrally directed branch from the cranioventrally directed nerve.

\section{Branches dispersing from the middle cervical ganglion}

\section{Cardiac nerves}

There were two or three cardiac nerves originating from the ventral and medial surface of the middle cervical ganglion. These cardiac nerves coursed ventrally or slightly caudoventrally to combine with other cardiac nerves forming a cardiac plexus (Figs. 1-5; $\mathrm{mc}$ and $\mathrm{Cp}$ ).

\section{The sympathetic-parasympathetic communicating branch}

There were three sympathetic-parasympathetic communicating branches joining the vagus nerve; two short branches directed ventrally and one long branch directed caudally. The two short ventrally directed branches originated from the ventral arch of the ovoid middle cervical ganglion to join the vagus nerve (Figs. 1-5; 1 and 2), and these two nerves are $5 \mathrm{~cm}$ long, $2 \mathrm{~cm}$ wide and $1 \mathrm{~cm}$ thick. 


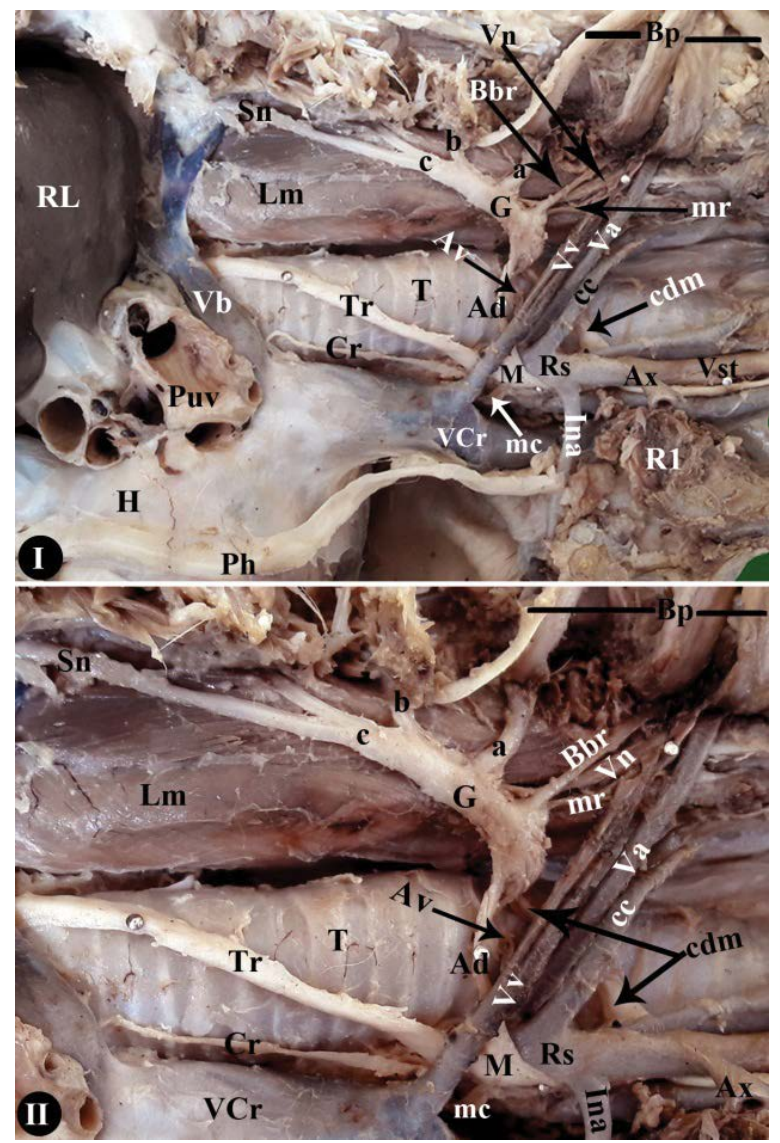

Figure 7. Gross anatomical photographs of lateral macroscopic appearance of the right cervicothoracic ganglion after the elevation of the brachial plexus (Bp); View I revelaed the presence of left subclavian vein and its branches while; View II revelaed the removal of left subclavian vein and its branches; $\mathrm{G}$ - right cervicothoracic ganglion; $\mathrm{M}$ - middle cervical ganglion; a — last (eighth) cervical sympathetic nerve; $b$ - first thoracic sympathetic ganglia; $\mathrm{c}$ - second thoracic sympathetic ganglia; $\mathrm{mr}$ - muscular branch from right cervicothoracic ganglia; $\mathrm{Bbr}$ - the ramus communicans combined with the last cervical spinal nerve to share in the formation of the brachial plexus; $\mathrm{Ad}$ - lateral small ansa subclavian nerve; $\mathrm{Av}$ - medial large ansa subclavia nerve; $\mathrm{cdm}$ - the cranioventrally directed nerve; $\mathrm{Vn}$ - vertebral nerve; $\mathrm{Cr}$ — the caudal cardiac nerve; $\mathrm{mc}$ - cardiac nerves; Rs — right subclavian artery; $\mathrm{Ax}$ - axillary artery; Ina — internal thoracic artery; cc — costocervical trunk; Lm — longus colli muscle; Vst — vagosympathetic trunk; $\mathrm{Sn}$ — sympathetic nerve; $\mathrm{Vv}$ — vertebral vein; $\mathrm{Va}$ — vertebral artery; $\mathrm{Sn}$ - sympathetic nerve; $\mathrm{VCr}$ - cranial venea cavae; $\mathrm{H}$ - heart; $\mathrm{Ph}$ - phrenic nerve; $\mathrm{T}$ - trachea; $\mathrm{Vb}$ - azygos vein; $\mathrm{RL}$ — right lung; Puv — pulmonary veins; $\mathrm{R} 1$ — first rib.

The long caudally directed branch measured about $5 \mathrm{~cm}$ in length, $2 \mathrm{~cm}$ in breadth and $1.5 \mathrm{~cm}$ in thickness and originated from the caudal angle of the middle cervical ganglion together with the pericardial branch (Figs. 1-5; 3 and Pr), and then directed caudally for $5 \mathrm{~cm}$ and united with the vagus nerve before the origin of the recurrent laryngeal nerve from the vagus
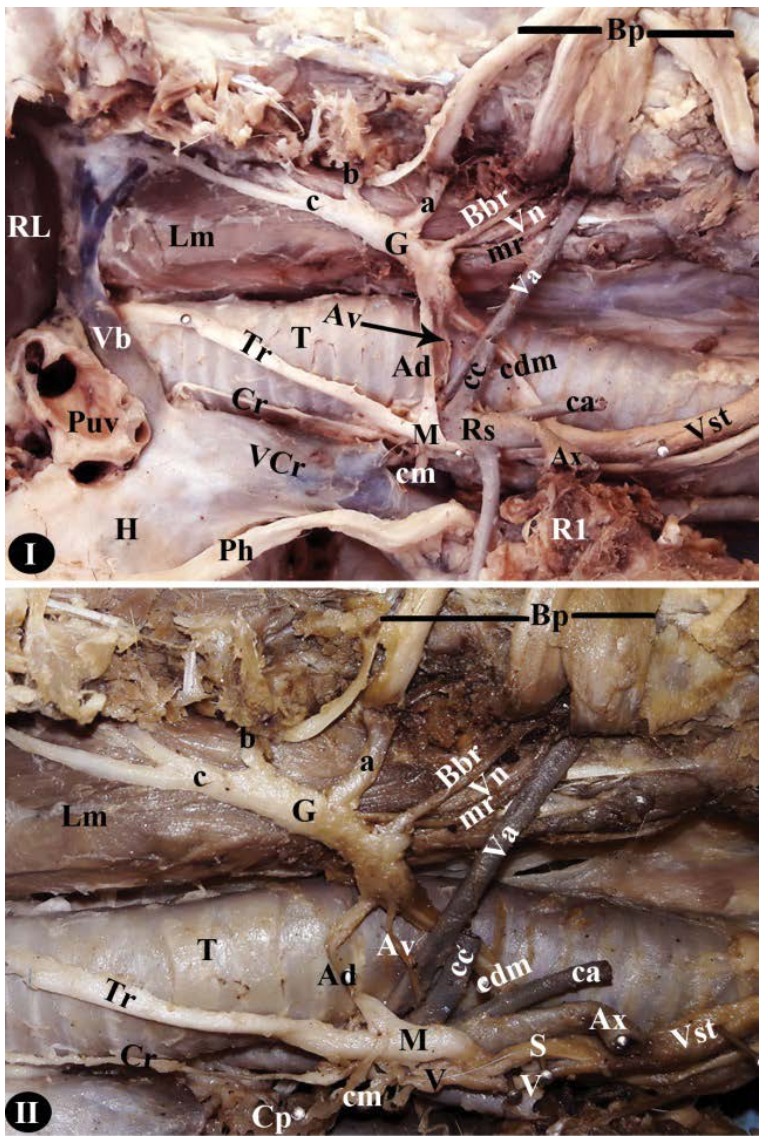

Figure 8. Gross anatomical photographs of lateral macroscopic appearance of the right cervicothoracic ganglion after the elevation of the brachial plexus (Bp); View I revealed the presence of left subclavian vein and its branches while; View II revealed the removal of left subclavian vein and its branches; $G$ - right cervicothoracic ganglion; $\mathrm{M}$ - middle cervical ganglion; a - last (eighth) cervical sympathetic nerve; $b$ - first thoracic sympathetic ganglion; $\mathrm{c}$ - second thoracic sympathetic ganglion; $\mathrm{mr}$ - muscular branch from right cervicothoracic ganglion; $\mathrm{Bbr}$ - the ramus communicans combined with the last cervical spinal nerve to share in the formation of the brachial plexus; Ad - lateral small ansa subclavia nerve; $\mathrm{Av}$ - medial large ansa subclavia nerve; $\mathrm{cdm}-$ the cranioventrally directed nerve; $\mathrm{Vn}$ - vertebral nerve; $\mathrm{Cr}$ - the caudal cardiac nerve; $\mathrm{cm}$ - cardiac nerves; $\mathrm{Cp}$ - cardiac plexus; Rs — right subclavian artery; $\mathrm{ca}$ - common carotid artery; $\mathrm{Ax}$ axillary artery; Ina - internal thoracic artery; cc — costocervical trunk; Lm — longus colli muscle; Vst — vagosympathetic trunk; $\mathrm{V}$ - vagus nerve; $\mathrm{S}$ - sympathetic nerve trunk; $\mathrm{Sn}$ - sympathetic nerve; $\mathrm{Vv}$ — vertebral vein; $\mathrm{Va}$ - vertebral artery; Sn — sympathetic nerve; $\mathrm{VCr}$ - cranial venea cavae; $\mathrm{H}$ - heart; $\mathrm{Ph}$ - phrenic nerve; $\mathrm{T}$ - trachea; $\mathrm{Vb}$ - azygos vein; $\mathrm{RL}$ — right lung; Puv pulmonary veins; R1 — first rib.

nerve by $1 \mathrm{~cm}$ (Fig. 4; 3,V and Rc), except in one case where it united with the vagus nerve after the origin of the recurrent laryngeal nerve by $1.5 \mathrm{~cm}$

\section{Pericardial branch}

It originated from the caudal angle of the middle cervical ganglion together with the long caudally 


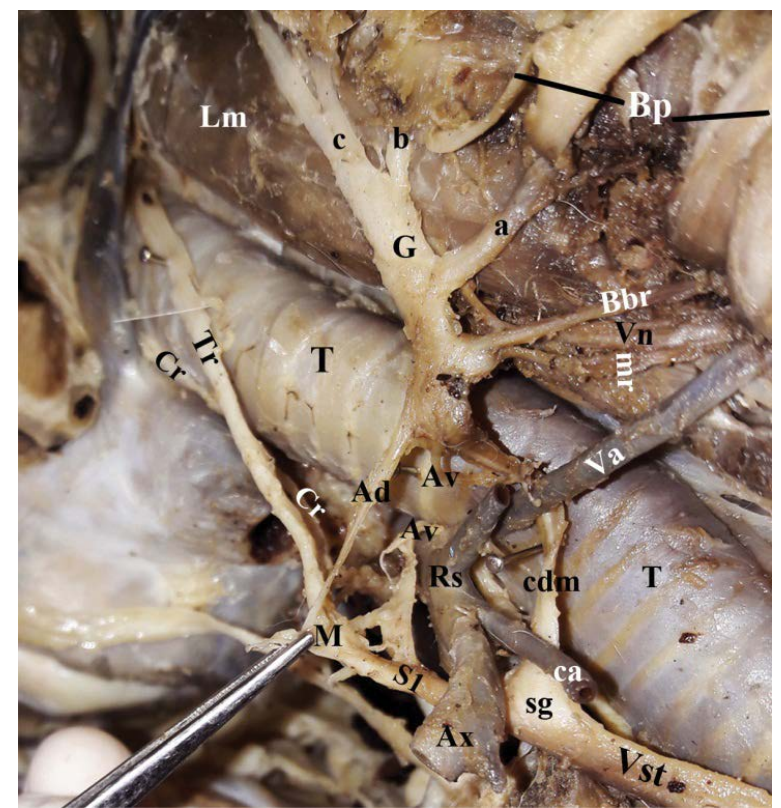

Figure 9. Gross anatomical photographs of the cranial macroscopic view of the right cervicothoracic ganglion after the elevation of the brachial plexus (Bp); $\mathrm{G}$ - right cervicothoracic ganglion; $\mathrm{M}$ - middle cervical ganglion; sg — small ganglion; a — last (eighth) cervical sympathetic nerve; $b$ - first thoracic sympathetic ganglion; c - second thoracic sympathetic ganglion; $\mathrm{mr}$ - muscular branch from right cervicothoracic ganglia; $\mathrm{Bbr}$ - the ramus communicans combined with the last cervical spinal nerve to share in the formation of the brachial plexus; $\mathrm{Ad}$ - lateral small ansa subclavian nerve; $A v$ - medial large ansa subclavia nerve; $\mathrm{cdm}$ - the cranioventrally directed nerve; $\mathrm{Vn}$ - vertebral nerve; $\mathrm{Cr}$ — the caudal cardiac nerve; $\mathrm{mc}$ — cardiac nerves; $\mathrm{S} 1$ communicating sympathetic branch between the middle and the small ganglia; Rs — right subclavian artery; ca — common carotid artery; Ax - axillary artery; Ina — internal thoracic artery; cc costocervical trunk; Lm — longus colli muscle; Vst — vagosympathetic trunk; V - vagus nerve; $\mathrm{Va}$ - vertebral artery; S — sympathetic nerve trunk; $\mathrm{Sn}$ - sympathetic nerve; $\mathrm{T}$ — trachea.

directed branch of the sympathetic-parasympathetic communicating branches (Figs. 1-4; 3 and Pr), and then directed caudoventrally to reach the pericardium above the left auricle, then it penetrates the pericardium to reach the wall of the left auricle (Fig. 5; Pr, pi and La).

\section{Anatomical description of the right cervicothoracic sympathetic system}

The right cervicothoracic sympathetic system was represented by two sympathetic ganglia: the caudal (cervicothoracic) and the middle cervical ganglion (Figs. 6-10; G and M). The caudal cervical ganglion was elongated, spindle in shape and located at the level of the second rib on the lateral surface of the longus colli muscle (Figs. 6-10; G and Lm), while the cranial $1 / 4$ of the ganglion was located in the groove

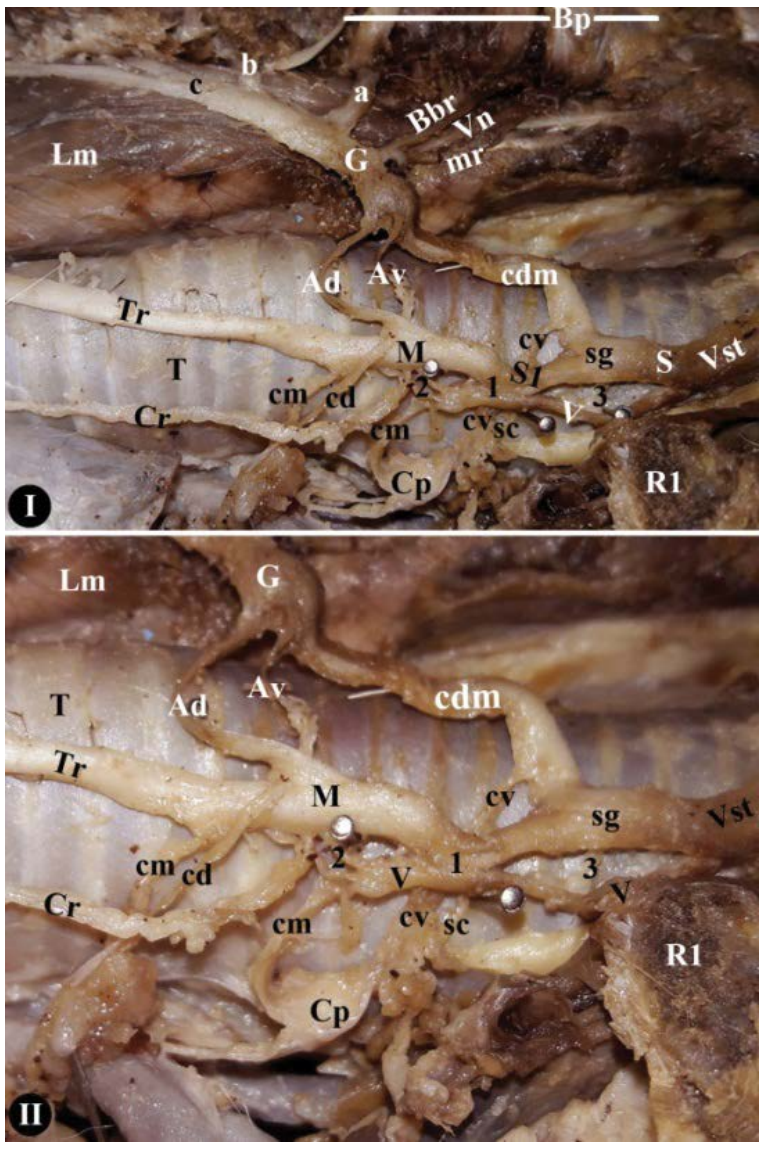

Figure 10. Gross anatomical photographs of lateral macroscopic appearance of the right cervicothoracic ganglion after elevation of brachial plexus (Bp); View I revealed the presence of left subclavian vein and its branches while; View II revealed the removal of left subclavian vein and its branches; $\mathrm{G}$ - right cervicothoracic ganglion; $\mathrm{M}$ - middle cervical ganglion; sg — small ganglion; $a$ - last (eighth) cervical sympathetic nerve; $b$ - first thoracic sympathetic ganglion; c - second thoracic sympathetic ganglion; $\mathrm{mr}$ - muscular branch from right cervicothoracic ganglion; $\mathrm{Bbr}$ - the ramus communicans combined with the last cervical spinal nerve to share in the formation of the brachial plexus; $\mathrm{Ad}$ lateral small ansa subclavia nerve; $A v-$ medial large ansa subclavia nerve; $\mathrm{cdm}$ - the cranioventrally directed nerve; $\mathrm{Vn}$ - vertebral nerve; $\mathrm{Cr}$ - the caudal cardiac nerve; $\mathrm{mc}$ - cardiac nerves; $\mathrm{Cp}$ - cardiac plexus; 1 and 2 - the two small sympathetic-parasympathetic communicating branches which originated from the middle cervical ganglion and directed ventrally to join with the vagus nerve; 3 - the sympathetic-parasympathetic communicating branch of the accessory small ganglion; $\mathrm{cv}$ — caudoventrally directed branch from the cranioventrally directed nerve; sc — the ventrally directed cardiac nerve from the small ganglia; $\mathrm{S} 1$ - communicating sympathetic branch between the middle and the small ganglia; $\mathrm{Lm}$ - longus colli muscle; Vst — vagosympathetic trunk; V — vagus nerve; $\mathrm{S}$ - sympathetic nerve trunk; $\mathrm{Sn}$ - sympathetic nerve; $\mathrm{Sn}$ - sympathetic nerve; $\mathrm{VCr}$ - cranial venea cavae; $\mathrm{T}$ - trachea; $\mathrm{Bbr}$ - the ramus communicans combined with the last cervical spinal nerve to share in the formation of the brachial plexus.

between the longus colli muscle and the trachea (Figs. 6-10; G, Lm and T). The cranial 1/2 of the examined ganglion was covered laterally by the second and 
third thoracic spinal nerve of the brachial plexus (Figs. 6-10; G, Bp and R2).

The right caudal cervical ganglion was located in the cranial $1 / 4$ of the quadrilateral venous area. This quadrilateral area was formed by: vertebral veins cranially, the right vena azygous caudally, the cranial vena cava ventrally, and the vertebral column dorsally (Figs. 7I and 8I; G, Vv, VCr and Vb).

In all examined dogs, the formation of the caudal cervical ganglion was achieved by the union of the last (eighth) cervical sympathetic nerve and the first two thoracic sympathetic ganglia. There were several rami communicants received by the caudal cervical ganglion, which originated from the eight cervical and the first two thoracic spinal segments. These rami communicants that originated from the first two thoracic spinal segments were united with the sympathetic trunk to combine with the caudal cervical ganglion at its craniodorsal angle (Figs. 6-10; b and c). The ramus communicans named eight cervical spinal segment was combined with the caudal cervical ganglion at its craniodorsal border (Figs. 6-10; a).

Middle cervical ganglion (Figs. 6-10; M) was ovoid in shape, and it was located at the same level of the caudal cervical ganglion, at the level of the second rib, nearly the ventrolateral surface of the trachea. The middle cervical ganglion was located on the lateral surface of the right subclavian artery and its caudal $1 / 4$ was covered laterally by the vertebral vein (Figs. 6-10; Rs and $\mathrm{Vv}$ ). The middle cervical ganglion was communicated with the caudal cervical ganglion by the two-nerve loop trunk named the ansa subclavia: the lateral and the medial nerve loop trunk (Figs. 6-10; Ad and Av). Furthermore, the middle cervical ganglion was communicated with the accessory small ganglion by the cranially directed nerve branch originated from the cranial angle of the middle cervical ganglion (Figs. 6-10; S1).

\section{Branches of the right caudal cervical ganglion The vertebral nerve}

The vertebral nerve (Figs. 6, 7; Vn) originated from the cranial part of the craniodorsal border of the caudal cervical (cervicothoracic) ganglion. Then, it passed under the last cervical spinal nerve in the craniodorsal direction. During its course, it was corresponding with the vertebral artery and vein (Fig. 7; Va and VV). After that, they passed under the transverse process of the seventh cervical vertebrae and enter the transverse foramen of the sixth cervical vertebrae.

\section{The ansa subclavian nerve}

The nerve loop trunk named the ansa subclavia consists of two nerve loops: the lateral and the media nerve trunk loop. The lateral nerve loop of the ansa subclavia (Figs. 6-10; Ad) originated from the cranial part of the caudoventral border of the caudal cervical ganglion and ran caudal to the origin of the medial nerve loop of the ansa subclavia by $0.3 \mathrm{~cm}$, and then it directed ventrally on the lateral surface of the trachea to enter the dorsal arch of the middle cervical ganglion.

The medial nerve loop of the ansa subclavia (Figs. 6-10; Av) originated from the cranial part of the caudoventral border of the caudal cervical ganglion, and then it directed ventrally directly on the lateral surface of the trachea and passed under the right subclavian artery to join the middle cervical ganglion at its medial surface. This nerve loop measured about $3.5 \mathrm{~cm}$ in length and $0.1 \mathrm{~cm}$ in width.

\section{The cranioventrally directed nerve}

This nerve originated from the cranial part of the caudoventral border of the caudal cervical ganglion (Figs. 6-10; cdm), and then it ran directed cranioventrally on the lateral surface of the trachea and joined the sympathetic nerve trunk before its union with the middle cervical ganglion forming a small sympathetic ganglion (Figs. 6-10; sg). The cranioventrally directed nerve measured about $4.5 \mathrm{~cm}$ in length and $0.3 \mathrm{~cm}$ in width and before its sharing in the formation of the small sympathetic ganglion by $1 \mathrm{~cm}$ it gave off a caudoventrally directed cardiac branch (Figs. 6-10; cv) of $4 \mathrm{~cm}$ in length to share in the cardiac plexus formation with other cardiac branches originating from the ansa subclavia and the middle cervical ganglion.

\section{The ramus communicans}

There was only one ramus communicans that was combined with the last cervical spinal nerve which sharing in the formation of the brachial plexus (Figs. 6-10; Bbr). This ramus communicans originated from the craniodorsal angle of the caudal cervical ganglion.

\section{Muscular branch}

There was only one muscular branch that originated from the craniodorsal angle of the caudal cervical ganglion (Figs. 6-10; mr). This branch was directed craniodorsally in corresponding with the vertebral nerve and ramus communicans and was combined 
with the last cervical spinal nerve, in which these three branches had the same origin from the craniodorsal angle of the caudal cervical ganglion.

\section{Branches of the middle cervical ganglion}

The sympathetic-parasympathetic communicating branch of the middle cervical ganglion

There were two smalls sympathetic-parasympathetic communicating branches of $0.7 \mathrm{~cm}$ in length (Figs. 6 and 10; 1 and 2), which originated from the middle cervical ganglion and directed ventrally to join the vagus nerve.

\section{The caudal cardiac nerve}

There were two or three cardiac nerves originating from the ventral and medial surface of the middle cervical ganglion (Figs. 6-10; $\mathrm{mc}$ ). These cardiac nerves coursed slightly caudoventrally to combine with other cardiac nerves originating from the lateral loop of ansa subclavia, cranioventrally directed nerve and small ganglia to form a cardiac plexus (Figs. 6-10; CP).

\section{Anatomical description of the accessory small ganglion}

There was a small ganglion located on the lateral surface of the trachea at the level of the first rib and cranial to the middle cervical ganglion by $1.2 \mathrm{~cm}$ (Figs. 6-10; sg). This ganglion formed by the union of the cranial sympathetic branch that originated from the cranial angle of the middle cervical ganglion with the cranioventrally directed nerve that originated from the caudal cervical ganglion (Figs. 6-10; cdm and S1). The sympathetic nerve trunk was joining the cranial angle of the accessory small ganglion.

\section{Branches of the accessory small ganglion}

The sympathetic-parasympathetic communicating branch of the accessory small ganglion

This was a small ventrally directed branch of $1 \mathrm{~cm}$ in length that originated from the ventral border of the accessory small ganglion to join the vagus nerve (Figs. 6 and 10; 3).

\section{The caudoventrally directed cardiac branch}

This was a small caudoventrally directed branch that originated from the caudal angle of the accessory small ganglion to share in the formation of the cardiac plexus (Figs. 6 and 10; sc).

\section{DISCUSSION}

The present study clarified that the Baladi dog had some anatomical variations in the position of the ganglia forming the cervicothoracic system on two sides; the left caudal cervical ganglion was located at the first intercostal space on the lateral surface of the longus colli muscle, while the right caudal cervical ganglion was located at the level of the second rib. This variation in the position of the ganglia forming the cervicothoracic system was reported previously by Ozgel et al. [19] in the donkey in which the left and right caudal cervical ganglia of the four examined donkeys were located at the level of the first intercostal space, but in one examined donkey, the left one was situated at the level of the second intercostal space, and in the area between the first and second intercostal spaces on the right side. In the horse [1], it was reported that the location of the left caudal cervical ganglion was cranial to the level of the first rib, but the right examined ganglion was located at the level of the first rib. However, there are numerous articles that noted that the left and right caudal cervical ganglia were located at the level of the first intercostal space $[8,12,19,20]$, while in the domestic animals König and Liebich [15] observed that the cervicothoracic ganglion was located at the level of the first rib.

The previously published articles reported the presence of the some anatomical variations about the presence the middle cervical ganglion $[6,10,15]$. The current work observed the presence of the middle cervical ganglion on both sides; this result is similar to that noted by Ozgel et al. [19] in the donkey, while in the horse [1] it was observed that the middle cervical ganglion was present on the right side and absent on the left side.

The current work agree with the observation noted by many authors that the caudal cervical ganglion was situated on the lateral surface of the longus colli muscle [8, 19, 21]; however, in the horse [1] it was reported that the left-sided caudal cervical ganglion was located on the lateral surface of the oesophagus, while the right-sided caudal cervical ganglion was located on the ventrolateral surface of the longus colli muscle and trachea. In the roe deer [12] it was noted that the caudal cervical ganglion was located on the border of the longus colli muscle. 
There are various appearances of the caudal cervical ganglion observed in the numerous published articles $[1,11,13,16,19-21]$. The current study reported that, the left caudal cervical ganglion was elongated triangular in shape with its apex directed ventrally, while the right one is elongated spindle in shape. The general appearance of the caudal cervical ganglion is a spindle-shape or star shape, similar to that observed by $[1,6,8,10,12,19,20]$. In the donkey, there were five different appearance of the caudal cervical ganglion (fusiform, star, oval, lunate, and irregular) described by Ozgel et al. [19], but only three different appearance were noted by Kabak et al. [12] and Pather et al. [20]. In the horse [1] it was reported that the left caudal cervical ganglion was stellate in shape and compressed from its centre, while the right caudal cervical ganglion was stellate and middle cervical ganglion was star.

Some published anatomical articles described the formation of the caudal cervical ganglion and observed some variations between different animals. The caudal cervical ganglion consisted of union of the last (eighth) cervical and the first thoracic sympathetic nerves $[5,19]$. However, the present study noted that the examined caudal cervical ganglion consisted of the union of the last (eighth) cervical and first two thoracic sympathetic nerves, this result was similar to those observed in roe deer and donkey $[12,19]$. It consisted of the union of the last (eighth) cervical and first three thoracic sympathetic nerves as reported in the dog [7] and horse [1]. Moreover, Chung et al. [3] and Evans and Lahunta [8] reported that the caudal cervical ganglion consisted of the union of the last (eighth) cervical and first four thoracic sympathetic nerves. However, in the human [20] it was reported that the caudal cervical ganglion consisted of the union of the last two cervical and the first thoracic sympathetic nerve, and in some cases the second [13] or occasionally the third and the fourth thoracic sympathetic nerves [2].

The present study observed that the left caudal cervical ganglion gave off the following branches: the vertebral nerve, the two branches forming the ansa subclavia, the nerve to the brachiocephalic trunk, muscular branches, and the ramus communicans to the first thoracic spinal nerve. However, the previous literature reports $[1,13,19,20]$ described that the caudal cervical ganglion gave the following branches: the vertebral nerve, the two branches forming the ansa subclavia, and the caudal cardiac nerve. The rami communicants joining the brachial plexus were also reported by $[1,19,20]$.

There are some minor variations in the origin of the vertebral nerve from the caudal cervical ganglion $[5,13]$. The present study observed that the left vertebral nerve originated from the cranial angle of the left caudal cervical ganglion, while the right vertebral nerve originated from the cranial part of the craniodorsal border of the caudal cervical ganglion. Abumadour and El-defrawy [1] and Ozgel et al. [19] observed that the vertebral nerve radiating from the craniodorsal angle of the caudal cervical ganglion.

The cardiac nerves were derived from the caudal cervical ganglion and sharing in the cardiac plexus formation $[1,13,19]$. In the present study, the cardiac nerves originated directly from the caudal and middle cervical ganglion. In addition, there were some cardiac nerves that originated from ansa subclavia, accessory cervical ganglion.

The present study reports the first record of the presence of the pericardial branch in the dog that originated from the caudal angle of the middle cervical ganglion, and then penetrated the pericardium to reach the wall of the left auricle. The pericardial branch was only reported previously in the horse [1].

The present study presents the first record of the sympathetic-parasympathetic communications branches, in which on the left side, there were three sympathetic-parasympathetic communicating branches that originated from the middle cervical ganglion to join the vagus nerve, while on the right side there were sympathetic-parasympathetic communicating branches to join the vagus nerve; two branches originated from the middle cervical ganglion, in addition to only one sympathetic-parasympathetic communications branch that originated from the accessory cervical ganglion. The sympathetic-parasympathetic communications branch was previous reported only by Ozgel et al. [19] in one donkey on the right side and by Abumadour and El-defrawy [1] on both sides of all examined horse.

\section{CONCLUSIONS}

In the current work, there was a right small ganglion in addition to the other three cervical ganglia: cranial, middle and caudal. The right small ganglion named the accessory cervical ganglion was found on the right side only and absent on the left. This right accessory ganglion was located on the lateral surface of the trachea at the level of the first rib. This gangli- 
on formed by the union of the cranial sympathetic branch that originated from the cranial angle of the middle cervical ganglion with the cranioventrally directed nerve that originated from the caudal cervical ganglion. In the roe deer [12] the presence of two accessory ganglions was observed, one on each side; the left one was located at the origin of the brachiocephalic trunk from the aortic arch, while the right one was located on the dorsal side of the trachea.

\section{Compliance with ethical standards}

The authors confirmed that the article do not contain any studies with human participants.

This study followed the guidelines for the care and use of laboratory animals and the animal welfare and was approved by the Ethics Committee of the Faculty of Veterinary Medicine, Alexandria University according the Egyptian laws. Adequate measures were taken to minimise pain or discomfort.

\section{Acknowledgements}

The authors extend their appreciation to the Deanship of Scientific Research at King Khalid University for funding this work through the Research Group Project under grant number (R.G.P.1/40/40).

Authors would like to thank the medical illustrator Ashraf Ragab Refaey, a student in the Faculty of Veterinary Medicine, Kafrelsheikh University for help in the design of the illustrated images (Figs. 1 and 6).

\section{Conflict of interest: None declared}

\section{REFERENCES}

1. Abumandour M, El-defrawy F. Morphological Investigations of the Cervicothoracic Sympathetic System in the Horse (Equus ferrus caballus) in Egypt. Int J Morphol. 2016; 34(3).

2. Arıncı $K$ and Elhan A. Anatomi, 2. Cilt, Gunes, Kitabevi LTD. STI, Ankara 1995.

3. Chung $\mathrm{IH}, \mathrm{Oh} \mathrm{CS}$, Koh KS, et al. Anatomic variations of the T2 nerve root (including the nerve of Kuntz) and their implications for sympathectomy. J Thorac Cardiovasc Surg. 2002; 123(3): 498-501, doi: 10.1067/mtc.2002.119340, indexed in Pubmed: 11882821.

4. Daniels TJ, Bekoff M. Population and social biology of free-ranging dogs, Canis familiaris. J Mammalogy. 1989; 70(4): 754-762.

5. Dursun N. Veteriner Anatomi II. Medisan Yayınevi, Ankara 2000.

6. Dyce KM, Sack WO, Wensing CJG. Text book of Veterinary anatomy. W.B. Saunders Company, Philadelphia, London and Toronto 2010.
7. Evans HE, Lahunta A. Guide to the dissection of the dog. 7th ed. Saunders Company, Philadelphia 2010.

8. Evans HE, Lahunta A. Miller's anatomy of the dog. 4th ed. W.B. Saunders Company, Philadelphia 2013: 1181.

9. Fioretto $E$, Guidi W, Oliveira P, et al. Macrostructure of the cranial cervical ganglionar complex and distal vagal ganglion during post natal development in dogs. Braz J Vet Res Animal Sci. 2003; 40(3), doi: 10.1590/s141395962003000300006.

10. Getty R. The anatomy of the domestic animals. Vol. 1, 5th ed. W.B. Saunders Company, Philadelpshia 1975.

11. Hogan QH, Erickson SJ. MR imaging of the stellate ganglion: normal appearance. AJR Am J Roentgenol. 1992; 158(3): 655-659, doi: 10.2214/ajr.158.3.1739014, indexed in Pubmed: 1739014.

12. Kabak M, Onuk B, Demirci B. Macroanatomical Investigation of the Cervicothoracic Ganglion in Roe Deer, Capreolus capreolus. Pakistan J Zool. 2015; 47(6): 1555-1561.

13. Kalsey G, Mukherjee RN, and Pa. Acomparative study of cervical sympathetic chain. J Anat Soc India. 2000; 49: 26-30.

14. Klećkowska J, Janeczek M, and Po. Analiza morfologiczna zwoju szyjno-piersiowego (ganglion cervicothoracicum) u 9-tygodniowych płodów świni. Medicina Veterinaria. 2003; 2(1): 41-47.

15. König HE, Liebich HG. Veterinary anatomy of domestic mammals. 3rd ed. Schattauer gimH, Holderlinstrabe, Germany 2007.

16. Marcer N, Bergmann M, Klie A, et al. An anatomical investigation of the cervicothoracic ganglion. Clin Anat. 2012; 25(4): 444-451, doi: 10.1002/ca.21266, indexed in Pubmed: 22488995.

17. Masliukov PM, Pankov VA, Strelkov AA, et al. Morphological features of neurons innervating different viscera in the cat stellate ganglion in postnatal ontogenesis. Auton Neurosci. 2000; 84(3): 169-175, doi: 10.1016/ S1566-0702(00)00208-3, indexed in Pubmed: 11111849.

18. Nomina Anatomica Veterinaria N. International Committee on Veterinary Gross Anatomical Nomenclature and authorized by the general assembly of the world Association of veterinary Anatomist. Knoxville, 3rd Ed. Ghent. Published by the Editorial Committee Hanover (Germany), Ghent (Belgium), Columbia, MO (U.S.A.), Rio de Janeiro (Brazil). 2017.

19. Ozgel O, Duzler A, Dursun N, et al. The morphology of the cervico-thoracic sympathetic system in donkeys (Equus asinus L.). Anat Histol Embryol. 2009; 38(2): 139-144, doi: 10.1111/j.1439-0264.2008.00912.x, indexed in Pubmed: 19183351.

20. Pather N, Partab P, Singh B, et al. Cervico-thoracic ganglion: its clinical implications. Clin Anat. 2006; 19(4): 323-326, doi: 10.1002/ca.20214, indexed in Pubmed: 16317739.

21. Phillips JG, Randall WC, Armour JA. Functional anatomy of the major cardiac nerves in cats. Anat Rec. 1986; 214(4): 365-371, doi: 10.1002/ar.1092140405, indexed in Pubmed: 3706781.

22. Rosse C, Gaddum-Rosse P. Hollinshead's Textbook of Anatomy. 5th Ed. Lippincott-Raven, Philadelphia 1997: 728-729.

23. Young J, Olson $K$, Reading $R$, et al. Is wildlife going to the dogs? Impacts of feral and free-roaming dogs on wildlife populations. BioScience. 2011; 61(2): 125-132, doi: 10.1525/bio.2011.61.2.7. 